\title{
Nursing Journalc
}

\author{
Cuidados paliativos: a atenção aos pacientes oncológicos \\ Palliative care: care for cancer patients \\ Cuidados paliativos: cuidados para pacientes con cáncer
}

\begin{abstract}
Aline Voltarelli ${ }^{1}$
ORCID: 0000-0002-3491-616X

Rosangela Sakman ${ }^{2}$

ORCID: 0000-0001-5881-9930

Maria Jose Leonardi ${ }^{3}$

ORCID: 0000-0001-5881-9930

Luis Carlos Ferreira ${ }^{4}$

ORCID: 0000-0002-8764-6968

Rulio Glécias Marçal da Silva ${ }^{5}$

ORCID: 0000-0002-9626-7361
\end{abstract}

${ }^{1}$ Faculdade de Mauá Fama/ União das Instituições Educacionais de São Paulo. São Paulo, Brasil. ${ }^{2}$ Faculdade Sequencial. São Paulo, Brasil.

${ }^{3}$ Faculdade Campo Limpo

Paulista. São Paulo, Brasil.

${ }^{4}$ Universidade de Guarulhos. São

Paulo, Brasil.

${ }^{5}$ União das Instituições

Educacionais de São Paulo. São

Paulo, Brasil.

\section{Como citar este artigo:}

Voltarelli A, Sakman R, Leonardi MJ, Ferreira LC, Silva RGM. Cuidados paliativos: a atenção aos pacientes oncológicos. Glob Acad Nurs.

2021;2(1):e83.

https://dx.doi.org/10.5935/2675-

5602.20200083

Autor correspondente:

Aline Voltarelli

E-mail: alivolter@yahoo.com.br

Editor Chefe: Caroliny dos Santos Guimarães da Fonseca

Editor Executivo: Kátia dos Santos Armada de Oliveira

\section{Resumo}

O presente estudo foi uma pesquisa acerca de cuidados paliativos voltados a pacientes oncológicos. A pesquisa para se alcançar tais resultados se deu de forma bibliográfica por meio de consulta e análise de vários autores e artigos. A principal finalidade desse trabalho é o de analisar a influência e o impacto da atenção dos profissionais de enfermagem na atuação com pacientes oncológicos em cuidados paliativos de acordo com a literatura existente. Ao final, esse ensaio elucidará a problemática central levantada em seu início a fim de dar o devido crédito aos cuidados médicos investigados, no que tangem às suas aplicações a pacientes oncológicos

Descritores: Cuidados Paliativos; Pacientes Oncológicos; Enfermagem; Oncologia.

\section{Abstract}

The present study was a research about paliativo care aimed at cancer patients. The search for the results of the results was done in a bibligraphic way through consultation and analysis of various authors and articles. The principal finalidade of this work is that of analisar a influência and the impact of the attention of nursing professionals in working with cancer patients in paliativos care according to the existing literatura. In the end, this teaching will elucidate the central issue that led to its beginning to give due credit to the medical care invested, as far as its applications to cancer patients are concerned.

Descriptors: Palliative Care; Oncological Patients; Nursing; Oncology.

\section{Resumén}

El presente estudio fue una investigación sobre la atención paliativa dirigida a pacientes con cáncer. La búsqueda de los resultados de estos resultados se llevó a cabo de forma bíblica a través de la consulta y análisis de diversos autores y artículos. El principal final de este trabajo es el de un analista y el impacto de la atención de los profesionales de enfermería en el trabajo con pacientes con cáncer en la atención paliativa de acuerdo con las leyes existentes. Al final, esta enseñanza aclarará el tema central que motivó su inicio para dar el debido crédito a la atención médica invertida, en cuanto a sus aplicaciones a los pacientes oncológicos.

Descriptores: Cuidados Paliativos; Pacientes Oncológicos; Enfermería; Oncología. 
Cuidados paliativos: a atenção aos pacientes oncológicos Voltarelli A, Sakman R, Leonardi MJ, Ferreira LC, Silva RGM

\section{Introdução}

Para os antepassados, a morte era percebida como uma fase natural da vida e, ao longo da evolução humana, a percepção da morte foi se transformando e tomando uma proporção diferenciada na vida das pessoas. Sendo necessário tratar daquele paciente, para o qual a ciência não possui recursos para deter o avanço fatal da doença, trazendo interrogações para a equipe de saúde, familiares e para o próprio indivíduo. O cuidado paliativo é mais que um método, é uma filosofia do cuidar. O cuidado paliativo se confunde historicamente com o termo hospice, que definia abrigos destinados a receber e cuidar de peregrinos e viajantes ${ }^{1,2}$.

Em 1982, o Comitê de Câncer da Organização Mundial da Saúde criou um grupo de trabalho responsável por definir políticas para o alívio da dor e cuidados do tipo hospice que fossem recomendados em todos os países para pacientes com câncer. O termo Cuidados Paliativos, já utilizado no Canadá, passou a ser adotado pelo OMS devido à dificuldade de tradução adequada do termo hospice em alguns idiomas. A OMS publicou sua primeira definição de Cuidados Paliativos em 1990 que foi revisada em 2002, como cuidados que melhoram a qualidade de vida dos doentes e de suas famílias, abordando os problemas associados às doenças que ameaçam a vida, prevenindo e aliviando o sofrimento através da identificação precoce e avaliação minuciosa da dor e outros problemas físicos, psicológicos, sociais e espirituais. Tendo este entendimento, o acesso aos cuidados paliativos é uma obrigação legal, como é reconhecida pelas convenções das Nações Unidas, e tem sido reclamado como um direito humano por associações internacionais, baseando-se no direito ao mais alto nível possível de saúde física e mental ${ }^{2,3}$.

Para os doentes que apresentam dor intensa, a não disponibilização de cuidados paliativos, por parte dos governos, pode considerar-se como um tratamento cruel, desumano ou degradante. O cuidado paliativo é uma abordagem terapêutica que envolve uma equipe multidisciplinar, incluindo várias especialidades médicas, enfermeiras, psicólogos, psiquiatras, nutricionistas, fisioterapeutas, fonoaudiólogos, assistentes sociais, farmacêuticos, conselheiros espirituais etc. Todos esses profissionais são importantes, uma vez que a Medicina Paliativa objetiva identificar e dirimir os problemas relacionados à internação nas esferas física, psicológica, espiritual ou social. Pressupõe-se que a visão da equipe de enfermagem diante dos cuidados paliativos ao paciente oncológico esteja incorporada aos aspectos humanistas onde os investimentos no processo de aprendizado estejam além do conhecimento técnico, que considera não somente a dimensão física, mas que busca oferecer apoio psicoafetivo, espiritual e social ao paciente ${ }^{4}$.

Sendo reconhecido que a empatia, atenção, compaixão e conforto sejam elementos necessários para que as demandas do cuidado do paciente sejam atendidas, reconhecendo o significado de cuidados paliativos. O estabelecimento de vínculos e atitudes capazes de oferecer estratégias de enfrentamento a partir do relacionamento estabelecido com o paciente é de suma importância para facilitação na prestação dos cuidados paliativos ${ }^{5}$. A principal finalidade desse trabalho é o de analisar a influência e o impacto da atenção dos profissionais de enfermagem na atuação com pacientes oncológicos em cuidados paliativos de acordo com a literatura existente.

\section{Metodologia}

Trata-se de uma Revisão Integrativa que, refere-se a um método que permite a síntese de múltiplos estudos publicados e possibilita conclusões gerais a respeito de uma particular área de estudo, na qual foi realizada de janeiro a maio de 2020. A revisão integrativa se deu em seis etapas: Fase 1 - Identificação do tema e hipótese de problema de pesquisa para elaboração da revisão integrativa; Fase 2 Estabelecimento de critérios para inclusão e exclusão dos estudos encontrados na busca da literatura; Fase 3 Categorização dos estudos e coleta de dados; Fase 4 Avaliação dos estudos incluídos na revisão integrativa; Fase 5 - Interpretação e discussão dos resultados; Fase 6 Redação do estudo.

Figura 1. Fluxograma de busca e seleção de estudos. São Paulo, SP, Brasil, 2020

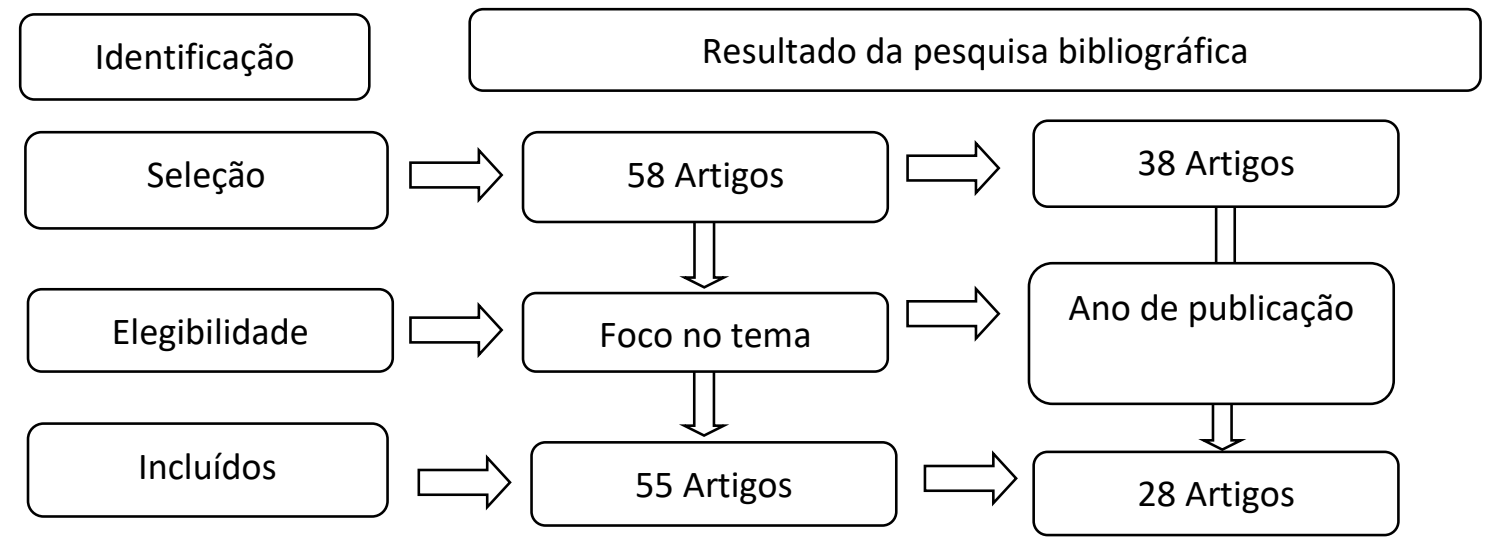

O estudo contemplou publicações: do tipo artigos científicos; selecionados os publicados no período de 2010 a 2020; disponíveis eletronicamente em texto completo; nas referidas bases de dados Literatura Latino-Americana e do Caribe em Ciências da Saúde (LILACS), Scientific Electronic Library Online (SciELO), Base de Dados em Enfermagem 
Cuidados paliativos: a atenção aos pacientes oncológicos Voltarelli A, Sakman R, Leonardi MJ, Ferreira LC, Silva RGM

(BDENF) e Literatura Internacional em Ciências da Saúde (MEDLINE); nos idiomas português, espanhol e inglês; e de acordo com os descritores: "Cuidados paliativos", "Pacientes oncológicos" e "Enfermagem".

Para a seleção dos artigos, foram estabelecidos os seguintes critérios de seleção: leitura do título e dos resumos que contemplassem o tema. Como critérios de exclusão, foram: artigos fora do período delimitado; não disponíveis em texto completo; livros, teses de doutorado, dissertações de mestrado; os que se repetiram na combinação dos descritores selecionados; e aqueles cujos assuntos não respondiam à questão norteadora da pesquisa ou não tinham relação com o objetivo da pesquisa. Utilizouse a terminologia em saúde consultada nos Descritores em Ciências da Saúde (DeCS) e no Medical Subject Headings (MeSH), pelos quais identificaram-se os descritores supracitados.

\section{Resultados}

Apresenta-se na Figura 2 os estudos selecionados para esta revisão.

Figura 2. Distribuição das publicações sobre cuidados paliativos na atenção aos pacientes oncológicos. São Paulo, SP, Brasil, 2020

\begin{tabular}{|c|c|c|c|c|}
\hline Autor & Ano & Método & Título & Resultados \\
\hline SEKI, N. H. & 2010 & $\begin{array}{l}\text { Pesquisa } \\
\text { bibliográfica }\end{array}$ & $\begin{array}{l}\text { O uso da música nos } \\
\text { cuidados paliativos: } \\
\text { humanizando o cuidado } \\
\text { e facilitando o adeus }\end{array}$ & $\begin{array}{l}\text { o uso de música tocada ao vivo, por voz e violão, foi não apenas } \\
\text { um instrumento importante para o processo de humanização do } \\
\text { cuidado e uma alternativa criativa e eficaz no alívio da dor, mas } \\
\text { também trouxe benefícios para a equipe de saúde, como: a } \\
\text { prevenção do estresse, a redução dos níveis da tensão e do } \\
\text { desgaste psicológico, maior interação social, e o maior } \\
\text { comprometimento com as atividades profissionais. }\end{array}$ \\
\hline $\begin{array}{l}\text { BASTOS, } \\
\text { B.R; } \\
\text { PEREIRA, } \\
\text { A.K.S; } \\
\text { CASTRO, } \\
\text { C.C; } \\
\text { CARVALHO } \\
\text {, M.M.C. }\end{array}$ & 2018 & $\begin{array}{l}\text { Estudo } \\
\text { retrospectivo } \\
\text {, descritivo e } \\
\text { transversal }\end{array}$ & $\begin{array}{l}\text { Perfil sociodemográfico } \\
\text { dos pacientes em } \\
\text { cuidados paliativos em } \\
\text { um hospital de } \\
\text { referência em oncologia } \\
\text { do estado do Pará, } \\
\text { Brasil }\end{array}$ & $\begin{array}{l}\text { Conhecer o perfil desses pacientes contribui para a compreensão } \\
\text { das peculiaridades desses indivíduos, auxiliando a equipe } \\
\text { multidisciplinar da clínica de cuidados paliativos no planejamento } \\
\text { da assistência prestada. Ao se delinear e sugerir intervenções aos } \\
\text { pacientes em cuidados paliativos, é fundamental que se considere } \\
\text { os recursos, a linguagem utilizada na orientação dos cuidados e o } \\
\text { tipo de população mais afetada pela doença. }\end{array}$ \\
\hline $\begin{array}{l}\text { ORGANIZA } \\
\text { ÇÃO } \\
\text { MUNDIAL } \\
\text { DE SAÚDE }\end{array}$ & 2009 & $\begin{array}{l}\text { Pesquisa } \\
\text { integrativa }\end{array}$ & $\begin{array}{l}\text { Serviços De Cuidado } \\
\text { Paliativo e Gestão Da } \\
\text { Qualidade }\end{array}$ & $\begin{array}{l}\text { Realizar o diagnóstico situacional- Avaliação dos pontos fortes e } \\
\text { fracos, identificação das diretrizes e ações, prazos e } \\
\text { responsabilidades. }\end{array}$ \\
\hline $\begin{array}{l}\text { MENDES, } \\
\text { E.C } \\
\text { VASCONCE } \\
\text { LLOS, L.C. F }\end{array}$ & 2015 & $\begin{array}{l}\text { Revisão } \\
\text { bibliográfica }\end{array}$ & $\begin{array}{l}\text { Cuidados paliativos no } \\
\text { câncer e os princípios } \\
\text { doutrinários do SUS }\end{array}$ & $\begin{array}{l}\text { À instrumentalização de uma política nacional de cuidados } \\
\text { paliativos que contemple o cidadão no direito de ter direito, no } \\
\text { direito de ter saúde e no direito de ter uma assistência no final da } \\
\text { vida, corresponde, consequentemente, o direito de ter uma } \\
\text { morte digna ou, melhor dizendo, um fim mais digno para a vida. }\end{array}$ \\
\hline $\begin{array}{l}\text { MENOSSI, } \\
\text { M. J.; } \\
\text { ZORZO, J. } \\
\text { C. C.; LIMA, } \\
\text { R. A. G. }\end{array}$ & 2012 & $\begin{array}{l}\text { Estudo } \\
\text { qualitativo }\end{array}$ & $\begin{array}{l}\text { A dialógica vida/morte } \\
\text { no cuidado do } \\
\text { adolescente com câncer }\end{array}$ & $\begin{array}{l}\text { Tomar decisões, relativas ao tratamento do adolescente e aos } \\
\text { modos de cuidar, faz a equipe aproximar-se da condição } \\
\text { complexa do ser humano, que tem implicações éticas, mas } \\
\text { também existenciais, trazendo ao profissional a sua própria } \\
\text { finitude. Deparar-se com sua própria finitude pode aproximar a } \\
\text { equipe de saúde do adolescente e de seus familiares que } \\
\text { experienciam a dor da provável perda. }\end{array}$ \\
\hline $\begin{array}{l}\text { FRATEZI, F. } \\
\text { R.; } \\
\text { GUTIERREZ } \\
\text {, B. A. O. }\end{array}$ & 2011 & $\begin{array}{l}\text { Estudo } \\
\text { qualitativo, } \\
\text { com roteiro } \\
\text { de entrevista } \\
\text { aberto e } \\
\text { semiestrutur } \\
\text { ado }\end{array}$ & $\begin{array}{l}\text { Cuidador familiar do } \\
\text { idoso em cuidados } \\
\text { paliativos: } \\
\text { o processo de morrer no } \\
\text { domicílio }\end{array}$ & $\begin{array}{l}\text { Tem-se que a relação de ajuda pode ser considerada como } \\
\text { essencial para auxiliar os cuidadores a lidarem com o processo de } \\
\text { morrer dos pacientes fora de possibilidades terapêuticas, bem } \\
\text { como com os encargos advindos da tarefa de } \\
\text { cuidar. }\end{array}$ \\
\hline $\begin{array}{l}\text { SALES, C. } \\
\text { A.; } \\
\text { D'ARTIBAL } \\
\text { E, E. F }\end{array}$ & 2011 & $\begin{array}{l}\text { Pesquisa } \\
\text { qualitativa }\end{array}$ & $\begin{array}{l}\text { Cuidar } \mathrm{Na} \\
\text { Terminalidade da Vida: } \\
\text { Escutando Os Familiares }\end{array}$ & $\begin{array}{l}\text { Ao desvelarmos os significados expressos pelos sujeitos, } \\
\text { apreendemos que a dimensão do sofrimento associado ao câncer } \\
\text { e à condição terminal gera nos familiares angústias, medos e } \\
\text { ansiedades, suscitando, assim, a necessidade de desenvolver uma } \\
\text { assistência que seja compatível com a condição vivenciada pelos } \\
\text { familiares, e vá ao encontro dos preceitos dos cuidados paliativos. }\end{array}$ \\
\hline $\begin{array}{l}\text { SILVA, A. } \\
\text { F.; ISSI, H. } \\
\text { B.; MOTTA, } \\
\text { M. G. C. }\end{array}$ & 2012 & $\begin{array}{l}\text { Estudo } \\
\text { qualitativo do } \\
\text { tipo } \\
\text { exploratório- } \\
\text { descritivo }\end{array}$ & $\begin{array}{l}\text { A Família da Criança } \\
\text { Oncológicar em } \\
\text { Cuidados Paliativos: O } \\
\text { Olhar da Equipe de } \\
\text { Enfermagem }\end{array}$ & $\begin{array}{l}\text { Este sentimento de preservação da existência, por outro lado, } \\
\text { acarreta um estado compassivo de atenção plena às abordagens } \\
\text { de cuidado singulares para cada criança e família em particular. }\end{array}$ \\
\hline
\end{tabular}


Cuidados paliativos: a atenção aos pacientes oncológicos Voltarelli A, Sakman R, Leonardi MJ, Ferreira LC, Silva RGM

\begin{tabular}{|c|c|c|c|c|}
\hline $\begin{array}{l}\text { SALOTTI, S. } \\
\text { R. A.; } \\
\text { GUIMARÃE } \\
\text { S, H. C. Q. } \\
\text { C.P }\end{array}$ & 2012 & $\begin{array}{l}\text { Estudo } \\
\text { transversal, } \\
\text { exploratório, } \\
\text { quantitativo } \\
\text { e qualitativo }\end{array}$ & $\begin{array}{l}\text { Enfrentamento do } \\
\text { paciente oncológico e } \\
\text { do familiar/cuidador } \\
\text { frente à terminalidade } \\
\text { de vida }\end{array}$ & $\begin{array}{l}\text { Aceitar a finitude é um processo complexo, mas quando um } \\
\text { paciente atinge a capacidade de entender a situação que está } \\
\text { vivendo e todas suas consequências, evidencia-se a aceitação da } \\
\text { morte e uma racionalização do sofrimento, que resulta na } \\
\text { elaboração de formas de enfrentamento de sua finitude. }\end{array}$ \\
\hline $\begin{array}{l}\text { HERMES, } \\
\text { H.R; } \\
\text { LAMARCA } \\
\text { I.C.A. }\end{array}$ & 2013 & $\begin{array}{l}\text { Revisão } \\
\text { bibliográfica }\end{array}$ & $\begin{array}{l}\text { Enfermeiros do Serviço } \\
\text { de Atendimento Móvel } \\
\text { de Urgência: perfil e } \\
\text { atividades } \\
\text { desenvolvidas }\end{array}$ & $\begin{array}{l}\text { O médico nos cuidados paliativos é um profissional importante. } \\
\text { Ele contribuirá para fornecer esclarecimentos sobre diagnósticos } \\
\text { e prognósticos para o paciente cuja morte é inevitável, } \\
\text { orientando a equipe, mantendo sempre uma boa comunicação } \\
\text { com os demais profissionais, para que o paciente tenha dignidade } \\
\text { nos últimos de sua vida. Portando quando não se pode mais curar, } \\
\text { ainda se pode cuidar e se ter uma boa relação entre médicos e } \\
\text { pacientes. }\end{array}$ \\
\hline $\begin{array}{l}\text { ATTY, } \\
\text { A.T.M; } \\
\text { TOMAZELL } \\
\text { I, J.G. }\end{array}$ & 2018 & $\begin{array}{l}\text { Estudo } \\
\text { descritivo }\end{array}$ & $\begin{array}{l}\text { Cuidados paliativos na } \\
\text { atenção domiciliar para } \\
\text { pacientes oncológicos } \\
\text { no Brasil }\end{array}$ & $\begin{array}{l}\text { Nos três anos analisados, mais de } 45 \% \text { dos encaminhamentos em } \\
\text { cuidados paliativos para atenção domiciliar foram realizados ela } \\
\text { atenção básica. Observa-se, também, pequeno aumento dos } \\
\text { encaminhamentos oriundos das internações hospitalares e uma } \\
\text { diminuição dos encaminhamentos feitos por centros oncológicos. }\end{array}$ \\
\hline $\begin{array}{l}\text { ANDRADE, } \\
\text { C.G, COSTA } \\
\text { S.F.G, } \\
\text { LOPES } \\
\text { M.E.L. }\end{array}$ & 2013 & $\begin{array}{l}\text { Pesquisa } \\
\text { exploratória, } \\
\text { de natureza } \\
\text { qualitativa }\end{array}$ & $\begin{array}{l}\text { Cuidados paliativos: a } \\
\text { comunicação como } \\
\text { estratégia de cuidado } \\
\text { para o paciente em fase } \\
\text { terminal }\end{array}$ & $\begin{array}{l}\text { A relevância do tipo de linguagem utilizada depende do grau de } \\
\text { comprometimento do paciente, porém é possível se comunicar } \\
\text { passando informações que confortam, esclarecem e dignificam a } \\
\text { finitude humana. Logo, o relacionamento interpessoal que ocorre } \\
\text { entre o enfermeiro e o paciente/familiar, no processo do cuidar, } \\
\text { tem sua essência nas habilidades de comunicação, e isso é } \\
\text { fundamental para que a assistência de enfermagem seja } \\
\text { humanizada. }\end{array}$ \\
\hline $\begin{array}{l}\text { ALVES, R. } \\
\text { F, MELO, } \\
\text { M; } \\
\text { ANDRADE, } \\
\text { S.; SOUSA, } \\
\text { V. }\end{array}$ & 2014 & $\begin{array}{l}\text { Pesquisa } \\
\text { quanti } \\
\text { qualitativa }\end{array}$ & 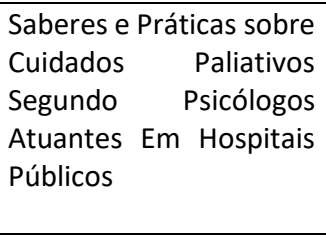 & $\begin{array}{l}\text { Indica fragilidade no preparo dos profissionais da saúde para o } \\
\text { exercício desses cuidados. Fato que compromete as assistências } \\
\text { aos pacientes terminais e leva ao aumento de um sofrimento que } \\
\text { poderia ser evitado. }\end{array}$ \\
\hline $\begin{array}{l}\text { MELO, A.C, } \\
\text { VALERO, } \\
\text { F.F, } \\
\text { MENEZES, } \\
\text { M. } \\
\end{array}$ & 2013 & $\begin{array}{ll}\text { Revisão } & \text { da } \\
\text { literatura } & \end{array}$ & $\begin{array}{l}\text { A Intervenção } \\
\text { Psicológica Em Cuidados } \\
\text { Paliativos }\end{array}$ & $\begin{array}{l}\text { Compreende-se, portanto, que a contribuição do profissional da } \\
\text { psicologia ocorre em diversas atividades, estas se dão a partir de } \\
\text { saberes advindos de uma visão do fenômeno como pertencente } \\
\text { ao campo da mente e das vivências e expressões pelo corpo. }\end{array}$ \\
\hline $\begin{array}{l}\text { PALMEIRA, } \\
\text { H.M; } \\
\text { SCORSOLI } \\
\text { NI-COMIN, } \\
\text { F.; PERES, } \\
\text { R.S. }\end{array}$ & 2011 & $\begin{array}{l}\text { Estudo } \\
\text { exploratório, } \\
\text { descritivo e } \\
\text { qualitativo }\end{array}$ & $\begin{array}{lr}\text { Cuidados } & \text { paliativos no } \\
\text { Brasil: } r \text { revisão } \\
\text { integrativa da literatura } \\
\text { científica }\end{array}$ & $\begin{array}{l}\text { Sem qualquer questionamento à qualidade da fonte dos demais } \\
\text { artigos, a preferência dos autores por revistas voltadas mais } \\
\text { especificamente a determinadas categoriais profissionais pode } \\
\text { ser considerada negativa porque não favorece a difusão do } \\
\text { conhecimento entre outras categoriais profissionais, o que, em } \\
\text { última instância, contraria a multidisciplinaridade inerente aos } \\
\text { cuidados paliativos. }\end{array}$ \\
\hline $\begin{array}{l}\text { ANDRADE, } \\
\text { CG; et al. }\end{array}$ & 2012 & $\begin{array}{l}\text { Revisão } \\
\text { integrativa }\end{array}$ & $\begin{array}{l}\text { Cuidados paliativos no } \\
\text { paciente idoso: uma } \\
\text { revisão integrativa da } \\
\text { literatura }\end{array}$ & $\begin{array}{l}\text { Assim, faz-se necessário que os profissionais se conscientizem do } \\
\text { caráter finito de sua própria vida, para que despertem o interesse } \\
\text { em aprender a respeito das formas humanas dignas de lidar com } \\
\text { a finitude do ser. }\end{array}$ \\
\hline $\begin{array}{l}\text { NUNES, } \\
\text { G. } \quad \text { S.; } \\
\text { RODRIGUE } \\
\text { S, B. } \text { M. R. } \\
\text { D }\end{array}$ & 2012 & $\begin{array}{l}\text { Estudo } \\
\text { fenomenológ } \\
\text { ico }\end{array}$ & $\begin{array}{l}\text { Tratamento Paliativo: } \\
\text { Perspectiva da Família }\end{array}$ & $\begin{array}{l}\text { Nesse sentido, cabe ao profissional valorizar as questões sociais } \\
\text { presentes no mundo da vida destes familiares que cuidam de um } \\
\text { familiar em assistência paliativa, bem como os significados dessa } \\
\text { vivência atribuídos por eles, às suas ações ou às suas interações. } \\
\text { Através da compreensão dos fenômenos se pode buscar um } \\
\text { cuidar mais autêntico. }\end{array}$ \\
\hline $\begin{array}{l}\text { SOUZA, M. } \\
\text { G. G.; } \\
\text { GOMES, A. } \\
\text { M. T. }\end{array}$ & 2012 & litativo & $\begin{array}{l}\text { Sentimentos } \\
\text { compartilhados por } \\
\text { familiares de pacientes } \\
\text { oncológicos } \\
\text { tratamento } \\
\begin{array}{l}\text { quimioterápico: um } \\
\text { estudo de } \\
\text { representações sociais }\end{array}\end{array}$ & $\begin{array}{l}\text { Ao mesmo tempo, essa experiência pode se apresentar como um } \\
\text { importante crescimento pessoal pelo conforto que se pode } \\
\text { proporcionar e pela recompensa profissional, por meio da } \\
\text { sensação de ter sido feito o máximo na tentativa de amenizar o } \\
\text { sofrimento do paciente e de sua família contribuindo, dessa } \\
\text { forma, com a melhora na qualidade de vida ou com o processo de } \\
\text { morte com dignidade. }\end{array}$ \\
\hline $\begin{array}{l}\text { NUNES, M. } \\
\text { G. S. }\end{array}$ & 2010 & $\begin{array}{l}\text { Estudo } \\
\text { qualitativo }\end{array}$ & $\begin{array}{l}\text { Assistência Paliativa em } \\
\text { Oncologia na } \\
\text { Perspectiva do Familiar: }\end{array}$ & $\begin{array}{l}\text { Oferecer uma forma de compreender o cuidado desse familiar, } \\
\text { situado no mundo institucional, possibilitando apreender o vivido } \\
\text { e os significados que alicerçam esta prática, conduz a um }\end{array}$ \\
\hline
\end{tabular}




\begin{tabular}{|l|l|l|l|}
\hline & & $\begin{array}{l}\text { Contribuições } \\
\text { Enfermagem }\end{array}$ & $\begin{array}{l}\text { comportamento, ações e relações; ou seja, um modo de pensar } \\
\text { que orienta o indivíduo em seu cotidiano para ser e estar com o } \\
\text { outro nessa fase da vida. }\end{array}$ \\
\hline
\end{tabular}

\section{Discussão}

Após o descobrimento da doença, é necessário avaliar se o tratamento adotado será realmente ideal para a melhoria do quadro clínico do paciente, verificando até mesmo se o assistido está dentro das possibilidades de ser atendido com práticas terapêuticas. Hoje em dia, algumas doenças estão fora da possibilidade de práticas terapêuticas, como: câncer, AIDS, doenças do sistema neurovegetativo e neurológicas progressivas, insuficiência cardíaca congestiva, insuficiência renal, doença pulmonar obstrutiva crônica e outras situações crônicas. Tal quadro, quando encontrado em crianças, solicita a atenção redobrada, pois as doenças são limitadores agressivos das atividades rotineiras, o que acarreta numa baixa de atividade muito drástica ${ }^{6}$.

É importante frisar que o câncer é o que possui maior apelo social, pois traz implícito outras doenças diversas, as quais possuem múltiplas causas e formas de diagnóstico e tratamentos. Tal abordagem traz qualidade de vida ao paciente durante os momentos finais de vida, tal prática paliativa é definida de acordo com cada paciente, e seu principal objetivo é diminuir a reverberação negativa da enfermidade, seja em ambiente domiciliar ou hospitalar. É demonstrado que, havendo a impossibilidade de ocorrer a cura, a prática terapêutica paliativa é um norteador a ser considerado dentro da abordagem de cuidados nos âmbitos físico, emocional, espiritual e social. Denota-se a importância do respeito ao entendimento sobre vida por parte do paciente e de seus familiares, o qual é fundamentado nas vivências individuais, costumes e crenças $^{6-8}$.

No que concerne aos amparadores, sejam eles cuidadores e/ou familiares, a terapia paliativa traz suporte também para quem enfrenta a construção do entendimento sobre a perda e o luto, a humanização é a peça chave do conceito dos cuidados paliativos, por meio de atividades multiprofissionais, onde é possível ensejar a elaboração de situações em pendência por parte dos familiares, e também que, posteriormente, seja um alicerce para a retomada das atividades individuais daqueles que ficam ${ }^{8}$.

A base familiar é constituída como sendo o primeiro momento de socialização de cada indivíduo, por meio dela aprendemos a conviver em sociedade, construímos valores e crenças que serão norteadores por toda a vida. A família é um núcleo constituído por seres humanos que se reconhecem por meio de laços afetivos, interesses em comum e consanguinidade dentro de um sistema histórico de vidas, independente de estes indivíduos compartilharem do mesmo ambiente. Muito importante destacar que, a partir desta nova abordagem, o termo denominado família não é só para os que possuem laços sanguíneos, mas também para àqueles onde existe a afetividade ${ }^{9,10}$.

O adoecimento não é um fato do indivíduo, pois também atinge aspectos físicos e que demandam reequilíbrio em diversas estruturas da vida familiar. Destacase que, perante o cometimento de uma enfermidade grave de um parente, as consequências para os demais integrantes podem gerar reações físicas, sociais e afetar diversas outras áreas, sentimento de culpa e impotência são os mais recorrentes; o indivíduo sendo integrante do núcleo biopsicossocial, que é a família, necessita de amparo, assim como também os demais integrantes que agem por ressonância diante da doença e do luto ${ }^{10,11}$.

Os familiares possuem necessidades especiais, pois passam por altas cargas de estresse e distúrbios de humor. A ocorrência de sentimentos duplos por parte dos familiares, diante da gravidade e da impossibilidade de cura, de outro lado podem ao mesmo tempo nutrir expectativas de prolongamento de tempo de vida. Vale salientar que a experiência do luto é vivenciada mesmo antes do óbito, o qual recebe o nome de luto antecipatório, durante tal processo, os familiares passam por fases de despedida do parente e do significado dentro da estrutura familiar, de forma gradual, o familiar tem a possibilidade de organizar sua estrutura emocional, possibilitando assim que seja amenizado o sofrimento da perda ${ }^{11}$.

Quando a finitude da vida torna-se algo tangível, é imprescindível que os familiares se sintam angustiados e vivenciem da dor intensa ${ }^{12}$. De acordo com a pesquisa, $61,90 \%$ dos artigos analisados tratam do tema relacionado à importância que o suporte aos familiares no momento do luto está relacionado à aceitação e ao engajamento da equipe multidisciplinar. Também foi possível observar que as crenças são importantes tanto para quem cuida quanto para o familiar, e que através da fé em algo superior, é possível ensejar fortalecimento e, assim, suportar a dor da doença e da perda. A religiosidade é muito recorrente dentro do estudo feito, sendo presente em $42,86 \%$ dos artigos estudados, sendo, através dela, possível alcançar conforto e alívio perante à enfermidade. Foi verificado que, não havendo religiosidade, alguns familiares enfrentaram maiores dificuldades na aceitação da perda, sendo a crença espiritual um ponto forte para manter o controle emocional de todos $^{13}$.

Esse novo ato faz com que o familiar desenvolva novos papéis, que jamais tinha feito antes, e que para maioria dos casos não possui qualificações. Em busca de manter equilíbrio familiar, tentar adaptar-se às situações que se apresentam em cuidar deste familiar adoecido. Quando um familiar pretende cuidar de um ente querido, seus sintomas psíquicos estão inter-relacionados com o cuidador, assim como o restante da família ${ }^{14}$.

Muitos são os motivos que fazem com que uma pessoa resolva cuidar de um ente da família, ou seja, essas decisões são baseadas geralmente em crenças e preceitos, como por exemplo, na intenção subjetiva, no sentimento de obrigação que um parente tem em não deixar seu familiar enfermo desamparado, em retribuir tanto na questão afetiva quanto financeira ${ }^{15}$.

Autores $^{16}$ destacam que os fatores, ou seja, os motivos para a escolha de um cuidador são: idade, grau de 
parentesco, gênero, proximidade da residência, afinidade, situação financeira e personalidade.

Quase sempre a decisão é pelo motivo da relação afetiva, ocorrendo um sentimento tanto de solidariedade quanto de respeito, ajudando a amenizar o sofrimento do paciente e do cuidador. Certamente os recursos pessoais e psíquicos influenciarão na forma do cuidado com aquele parente. Cabe destacar que, muitas vezes, a família não ficará satisfeita com aquele cuidado realizado pelo cuidador e, dada insatisfação gerará conflitos dentro da própria família e, caso estes não sejam resolvidos, poderão prejudicar toda a estrutura de afeto na família.

$O$ ato de cuidar é muitas vezes dispendioso e causa uma transformação emocional, financeira e física, mas quando esse ato é positivo, ou seja, com sentimentos positivos, sentimentos como carinho, satisfação e zelo, acabam surgindo. Contudo, se os sentimentos não forem positivos, e sim negativos, os cuidados e sentimentos do cuidador mostrarão incômodo, falta de zelo e tristeza. Para ser um cuidador, é algo difícil e demorado, e só se aperfeiçoará com o passar do tempo e com a segurança repassada pelo restante da família e do enfermo no decorrer do tempo ${ }^{17}$.

Sentimentos, como depressão, solidão, ansiedade, rodeiam os pensamentos do cuidador familiar diante de todo o processo de doença e morte de seu ente querido ${ }^{18}$.

Existem também sentimentos de amor e ódio do cuidador pelo doente membro familiar. A questão financeira é fator primordial para a maioria dos casos e considerada de extrema importância, uma vez que o cuidador deixará de cuidar da sua própria vida, e passará mais tempo se dedicando ao doente. Ao analisar essas consequências é possível perceber que o cuidador fica mais vulnerável a doenças físicas.

O estresse que há durante o processo de cuidado do ente familiar poderá fazer com que o cuidador fique doente, pois segundo estudos ${ }^{19,20}$, cuidar de um adulto dependente é desgastante e implica em riscos de tornar doente e igualmente dependente o cuidador. Além disso, o cuidador pode ter sua vida social prejudicada, como por exemplo o isolamento de demais pessoas do seu convívio. Alguns cuidadores não conseguem deixar a vida antiga e, com isso, acabam não dando atenção às necessidades presentes ${ }^{20}$.

Desta forma, o bem-estar daquele que cuida do enfermo familiar piorará, se agravará, estando ligado à saúde do doente, causando sérios sentimentos de depressão e ansiedade. O processo de adaptação do cuidador é lento e deve ser sempre verificado pelo restante da família ou por um médico, porque cuidar de alguém gerará mais trabalho e responsabilidade para o cuidador, aliando-se a uma maior sobrecarga e diminuição de tempo para a vida do cuidador, afetando e desgastando o mesmo.

\section{Conclusão}

O habitus profissional identificado corresponde ao conceito primário de conforto para um tratamento que não mais impactará na cura de um paciente oncológico em cuidados paliativos. A ausência de formação e protocolo específico para a conduta com cuidados paliativos não interfere na autopercepção individual de domínio e aptidão para com o tratar desses pacientes. Há ainda um desconforto geral entre todas as categorias no que tange à incerteza da definição do tratamento.

Os profissionais de enfermagem são os que mais percebem tal condição de dúvida para com a continuidade ou não de um tratamento terapêutico, ainda que os profissionais médicos afirmem dar diagnósticos assertivos. No contexto hospitalar, a equipe multidisciplinar atua sem procedimento, na grande maioria das vezes, pautada pelo parecer dos profissionais médicos. Essa conduta prática se mostra ruim, não somente pela falta de normas padrões que todos possam seguir, mas também pelo fato já declarado das situações em que os pares de profissionais médicos, que atuam em turnos distintos, não possuem um acordo definitivo sobre os pacientes em cuidados paliativos.

Esta pesquisa também visou analisar as situações de muitas famílias, diante de uma doença de um ente querido, as quais necessitam de um cuidador, permitindo analisar as dificuldades que o cuidador possui diante dos problemas enfrentados cotidianamente. Diante disso, os cuidados paliativos são uma forma de tentar proporcionar, tanto para o cuidador, família e paciente, uma certa dignidade, recebendo apoio durante todo o processo de doença do enfermo e suporte em caso de ocorrência de morte. Há a necessidade de criação de um grupo de cuidados paliativos multiprofissional e de suporte familiar que apoie e complemente a enfermagem, em especial, nas situações de cuidados paliativos a pacientes oncológicos.

A partir da demanda premente de um grupo que oferecesse palestras, melhoria da comunicação multiprofissional e outras maneiras de formação continuada específica da área, seria algo bem vindo e necessário à melhoria da eficiência do trato da modalidade de cuidados paliativos em pacientes terminais cancerígenos. Além disso, a criação de protocolos específicos e padronizados para as instituições hospitalares é o fator fundamental para o bom funcionamento de um grupo com tal finalidade

\section{Referências}

1. Seki NH, Galheigo SM. O uso da música nos cuidados paliativos: humanizando o cuidado e facilitando o adeus. Interface (Botucatu). 2010 Jun; 14(33): 273-284.

2. Bastos BR, Pereira AKS, Castro CC, Carvalho MMC. Perfil sociodemográfico dos pacientes em cuidados paliativos em um hospital de referência em oncologia do estado do Pará, Brasil. Rev. Pan-Amaz Saúde. 2018 jun; 9(2): 31-36.

3. Fonseca JVC, Rebelo T. Necessidades de cuidados de enfermagem do cuidador da pessoa sob cuidados paliativos. Rev. Bras. Enferm. 2011; 64(1):180-184.

4. Organização Mundial de Saúde. Serviços de cuidado paliativo e gestão da qualidade. Genebra (CH): OMS, 2009. 
Cuidados paliativos: a atenção aos pacientes oncológicos Voltarelli A, Sakman R, Leonardi MJ, Ferreira LC, Silva RGM

5. Mendes EC, Vasconcellos LCF.Cuidados paliativos no câncer e os princípios doutrinários do SUS. Saúde Debate. 2015; 39(106):881-892.

6. Menossi MJ, Zorzo JCC, Lima RAG. A dialógica vida/morte no cuidado do adolescente com câncer. Rev Latino-Am Enferm. 2012; 20(1):126134.

7. Fratezi FR, Gutierrez BAO. Cuidador familiar do idoso em cuidados paliativos: o processo de morrer no domicílio. Ciência \& Saúde Coletiva. 2011; 16(7):3241-3248.

8. Sales CA, D’Artibale EF. O cuidar na terminalidade da vida: escutando os familiares. Ciênc. cuid. Saúde. 2011; 10(4).

9. Silva AF, Issi HB, Motta MGC. A família da criança oncológica em cuidados paliativos: o olhar da equipe de enfermagem. Ciência \& Saúde Coletiva. 2011; 10(4):820-827.

10. Salotti SRA, Guimarães HCQCP. Enfrentamento do paciente oncológico e do familiar/cuidador frente à terminalidade de vida. J. Revista Instituto de Ciências da Saúde. 2012; 30(3);235-240.

11. Hermes HR, Lamarca ICA. Cuidados paliativos: uma abordagem a partir das categorias profissionais de saúde. Ciênc. saúde coletiva. 2013 Sep; 18(9):2577-2588.

12. Atty ATM, Tomazelli JG. Cuidados paliativos na atenção domiciliar para pacientes oncológicos no Brasil. Saúde Debate. 2018; 42(116):225236.

13. Andrade CG, Costa SFG, Lopes MEL. Cuidados paliativos: a comunicação como estratégia de cuidado para o paciente em fase terminal. Ciênc. saúde coletiva. 2013 Sep; 18(9):2523-2530.

14. Alves RF, Melo M, Andrade S, Sousa V. Saberes e práticas sobre cuidados paliativos segundo psicólogos atuantes em hospitais públicos. Psic., Saúde \& Doenças. 2014 Mar; 15(1):77-95.

15. Melo AC, Valero FF, Menezes M. A intervenção psicológica em cuidados paliativos. Psic, Saúde \& Doenças. 2013 nov; 14(3):452-469.

16. Palmeira HM, Scorsolini-Comin F, Peres RS. Cuidados paliativos no Brasil: revisão integrativa da literatura científica. Aletheia. 2011 dez; 35(36):179-189.

17. Andrade CG, et al. Cuidados paliativos no paciente idoso: uma revisão integrativa da literatura. Revista bras Ciênc Saúde. 2012; 16(3):411418.

18. Nunes MGS, Rodrigues BMRD. Tratamento paliativo: perspectiva da família Revista de Enfermagem UERJ. 2012; 20(3):338-343.

19. Souza MGG, Gomes AMT. Sentimentos compartilhados por familiares de pacientes oncológicos em tratamento quimioterápico: um estudo de representações sociais. Rev Enferm. 2012; 20(2):149-154.

20. Nunes MGS. Assistência paliativa em oncologia na perspectiva do familiar: contribuições da enfermagem. 2010. $82 \mathrm{f}$. Dissertação (Mestrado) - Universidade do Estado do Rio de Janeiro, Rio de Janeiro. 2010. 